\title{
Control of active $B$ and $L$ cathepsins in tissues of colorectal cancer using cystatins isolated from chicken egg proteins: in vitro studies
}

\author{
Andrzej Hap ${ }^{1}$, Wojciech Kielan², Zygmunt Grzebieniak², Maciej Siewinski ${ }^{3}$, Jerzy Rudnicki ${ }^{4}$, \\ Robert Tarnawa², Julia Rudno-Rudzinska², Anil Kumar Agrawal² \\ ${ }^{1}$ Department of Surgery, Regional Hospital, Legnica, Poland \\ ${ }^{2} 2^{\text {nd }}$ Department of General and Oncological Surgery, Medical University of Wroclaw, Poland \\ ${ }^{3}$ Faculty of Public Health, Medical University of Wroclaw, Poland \\ ${ }^{4}$ Department of Minimally Invasive Surgery and Proctology, Medical University of Wroclaw, Poland
}

\begin{abstract}
The activity of cysteine peptidases (cathepsins B and L) was estimated in homogenates of tissues sampled during surgery from 60 patients operated due to colorectal tumors. The results were compared to those obtained using tissues in which histopathology disclosed no tumorous cells, obtained from 20 patients of the same group, treated as a control. Activity of the enzymes was inhibited using cysteine peptidase inhibitors isolated from chicken egg proteins. Application of the inhibitors was found to inhibit activity of the enzymes which play a key role in tumor development. It is suggested that in future the inhibitors may provide a component of new generation drugs in the so-called inhibitor therapy. (Folia Histochemica et Cytobiologica 2011; Vol. 49, No. 4, pp. 670-676)
\end{abstract}

Key words: large intestine, cystatins, cathepsins

\section{Introduction}

The incidence of malignant colorectal tumors is very high: it is estimated that $6 \%$ of the human population will develop colorectal cancer during their life, and $40 \%$ of those will die because of the tumor [1]. An increased prevalence of tumors has been noted in industrialized regions, which is linked to elevated levels of toxic substances emitted to the atmosphere [2]. Epidemiological and statistical results of studies conducted in Poland to date have confirmed that around $60 \%$ of tumors were induced by agents representing environmental pollution with carcinogens [3]. Reports suggest that probably in tumors of the alimentary tract at first a suppressor gene appears,

Correspondence address: A.K. Agrawal,

$2^{\text {nd }}$ Department of General and Oncological Surgery,

Medical University of Wroclaw,

Borowska Str. 213, 50-556 Wroclaw, Poland;

e-mail: dranilpreeti@gmail.com the altered APC gene, located on chromosome 5 (MCC-mutated in colorectal cancer) and DCC (deleted in colorectal carcinoma) genes, coding for proteins responsible for cellular adhesion, which subsequently control interaction of the neoplastic cell with normal cells. Finally, the changes may lead to development of a tumor. The multi-step process of changes in a tumor of alimentary tract (polyp $\rightarrow$ carcinoma) involves few gradual mutations in a genome of normal cells $[4,5]$.

The results of studies conducted by several independent teams suggest that the changes involve the so-called cascade of enzymatic alterations. The process reflects the fact that enzymes involved in the process participate in reciprocal autoactivation. At the beginning, they appear in the human body in the form of inactive precursors, which do not manifest their biological function until they are enzymatically activated $[6,7]$. Justifiable assumptions have been put forward that the cause of appearance and development of neoplastic processes involves overexpression 
of proteolytic enzymes, compared to an activity of cathepsins produced in the body their autogenic inhibitors, capable of inhibiting activity of the proteases. The correlation between active metalloproteinases, elastases, plasminogen activator and their autogenic inhibitors has been dissected in detail [8]. Inhibitors of cysteine peptidases have been also examined, which by inhibition of cathepsin B and L may additionally restrict formation of collagenase, elastase, collagen activator and other metalloproteinase active forms or key enzymes involved in the decomposition of normal tissues. It is assumed that the process may be controlled using inhibitors isolated from various extracorporeal sources. The appearance in a body of active cathepsin $\mathrm{D}$ results in activation of cysteine peptidases (mainly cathepsins B and L). Results of studies have confirmed that appearance of the enzyme's active forms results in activation of several proteolytic enzymes from their inactive precursors, including, first of all, metalloproteinases, plasminogen activator, elastases and several other enzymes. In parallel with cysteine peptidases, the enzymes induce degradation of their own tissues. They are also decisive for processes associated with neoplastic alterations, such as transformation of normal to neoplastic cells, invasion and development of metastases or angiogenesis.

However, no inhibitors have been obtained until now which would inhibit the activity of the enzymes in vivo but which exert no toxicity [9-12]. Activity of proteolytic enzymes associated with neoplasia is controlled by their specific inhibitors, manifested in the body as autogenic inhibitors. Japanese investigators have demonstrated a significant involvement of autogenic cystatin $\mathrm{SN}$ in the development of lesions in a colorectal tumor. A significant correlation was disclosed of the enzyme level and markers such as CEA and CA19-9, estimated by the ELISA technique [13]. In this case, research results from another Japanese team proved extremely interesting. They demonstrated a very high similarity between the structure of cystatin $\mathrm{SN}, \mathrm{C}$ and its analog isolated from egg proteins. It may be assumed that cystatin obtained from egg proteins may interchangeably be applied with inhibitors of cysteine peptidases, which control overexpression of cathepsins, cysteine peptidases in pathogenic conditions, including cathepsins B, L or K in colorectal cancer [14].

\section{Material and methods}

Tissue samples of around $1 \mathrm{~g}$ were sampled intraoperatively from 60 patients with a diagnosis of colorectal adenocarcinoma and were stored in a freezer at a temperature of $-20^{\circ} \mathrm{C}$ for around three months. Apart from the known and applied routine diagnostic techniques performed before the procedure, histopathology was also applied. The control group included tissue samples free of cancerous lesions. The age of the operated patients of either sex ranged between 35 and 73 years. Tumor advancement was evaluated in routine histopathological examination, using hematoxylin- and eosin-stained preparations (H\&E evaluation). Estimation of cancerous cell presence followed rules provided by UICC, based on the TNM scheme ( $\mathrm{T}$ - tumor size, $\mathrm{N}$ - node invasions, $\mathrm{M}$ - metastasis). In the modified scale of Dukes, the tissues originated from ten patients $(17 \%)$ representing tumor advancement stage A, from 20 patients (33\%) with stage $\mathrm{B}, 12$ patients $(20 \%)$ with stage $\mathrm{C}$, and 18 patients $(30 \%)$ with stage D [15].

After collecting 20 to 30 samples, they were thawed, washed with saline and divided into two parts. One was embedded in paraffin and subjected to immunohistopathological examination, and the other was homogenized in a triple amount (weightwise) of $10 \mathrm{mM}$ Tris-HCl buffer, $\mathrm{pH}$ 7.4, supplemented with $0.25 \mathrm{M}$ sucrose, $1 \mathrm{mM}$ DTT (dithiothreitol), $0.1 \mathrm{mM}$ ATP (adenosine-triphosphate) and $0.1 \mathrm{mM} \mathrm{CaCl}_{2}$. The homogenates were centrifuged at 100,000 g for one hour at $4^{\circ} \mathrm{C}$. After centrifugation the supernatant was collected and stored at $-70^{\circ} \mathrm{C}$. After 60 samples of cancerous tissues were processed in this way, activity of their cysteine proteases was estimated using spectrofluorometry.

Estimation of cathepsin $B$ and $L$ activities. Activities of cathepsins B and L were estimated using spectrofluorometric technique of Barrett [16]. Z-Arg-AMC, i.e. benzyloxycarbonyl-arginyl-AMC (AMC, alpha methylcoumarin) served as a substrate. Following hydrolysis, fluorescence of the released 7-AMC was measured using a spectrofluorimeter (Perking Elmer LS 50 B, using illumination at $440 \mathrm{~nm}$ and measuring emission at $370 \mathrm{~nm}$ ). The fluorescence was read out using a calibration curve prepared using 7-AMC. A unit of enzymatic activity (U) involved the amount of enzyme, calculated per protein, which catalyzed release of $1 \mathrm{nM}$ of 7-AMC per minute.

Inhibitory activity in studied samples was estimated using the technique of Heidtman [17]. A single unit of inhibitory activity was defined as such an amount of an inhibitor which inhibited respectively cathepsin B and L activities calculated per $1 \mathrm{mg}$ of protein [18]. The calculations took advantage of Statgraf software. Distribution of the results was tested using the test of Kolmogorov-Smirnov. All the examined characters manifested the normal distribution, which in statistical analysis permitted to apply parametric tests. Comparison of values between two studied parameters employed Student's $t$ test, non-parametric tests of Wilcox or Kruskall-Wallis. Correlation coefficients were calculated using Student's $t$ test for correlation coefficient. All hypotheses were tested at the significance level of $p<0.05$. 
Table 1. Activity of cathepsins B and L in tissue homogenates obtained from 60 patients operated due to a colorectal tumor, compared to the control group of healthy tissues (344.8 units/mg protein)

\begin{tabular}{|l|c|c|c|}
\hline Cysteine peptidases in & Mean \pm SD & Range & SD \\
\hline Tumor $(\mathrm{n}=60)$ & 286.50 & $403.20-135.10$ & 60.16 \\
\hline Control $(\mathrm{n}=20)$ & $18.7 \pm 8.1$ & $12.3-26.9$ & 15.4 \\
\hline
\end{tabular}

Difference between the two groups significant at $\mathrm{p} \leq 0.0001$

Table 2. Titration of cathepsin B and $\mathrm{L}$ activities using cystatin obtained from egg proteins in three selected samples of tissue homogenate obtained from colorectal cancer

Activity of cystatin: 344.8 units/mg protein

\begin{tabular}{|c|c|c|c|}
\hline $\begin{array}{l}\text { Activity of cystein } \\
\text { peptidases/1.0 mg protein }\end{array}$ & $\begin{array}{c}+25 \mu \mathrm{g} \mathrm{ICP} / \\
/ 1.0 \mathrm{mg} \text { protein }\end{array}$ & $\begin{array}{c}+50 \mu \mathrm{g} \mathrm{ICP} / \\
/ 1.0 \mathrm{mg} \text { protein }\end{array}$ & $\begin{array}{c}+100 \mu \mathrm{g} \mathrm{ICP} / \\
/ 1.0 \mathrm{mg} \text { protein }\end{array}$ \\
\hline $262.8(100 \%)$ & $192.1(73.8 \%)$ & $90.1(65.7 \%)$ & $13.6(5.2 \%)$ \\
\hline $345.5(100 \%)$ & $271.7(78.6 \%)$ & $156.2(54.8 \%)$ & $58.9(17.1 \%)$ \\
\hline $264.1(100 \%)$ & $207.8(78.7 \%)$ & $86.1(67.4 \%)$ & $23.8(9.0 \%)$ \\
\hline
\end{tabular}

Table 3. Activity of cysteine peptidases in tissue homogenates of patients operated due to tumor of large intestine compared to control group (healthy tissues) (344.8 U/ mg protein)

\begin{tabular}{|l|c|c|c|}
\hline Cathepsin in & Mean \pm SD & Range & SD \\
\hline Tumor & 286.50 & $403.20-135.10$ & 60.15 \\
\hline Control & 142.86 & $252.60-4.80$ & 40.63 \\
\hline$\%$ inhibition & 49.86 & $67.00-33.00$ & 7.81 \\
\hline
\end{tabular}

The difference is significant at $\mathrm{p} \leq 0.0001$

\section{Results}

In the study, cysteine peptidase (cathepsins B and L) activity was estimated in homogenates of tissues sampled during surgery from 60 patients operated due to tumors of the large intestine. The results were compared with biological material obtained from 20 patients of the same group, in which histopathology failed to disclose the presence of cancerous cells. The latter samples provided a control group. Activity of the enzymes was inhibited using cystatin isolated from hen eggs, which manifested activity of 344.8 units per mg protein. The amount of the inhibitor was adjusted so that activity of the enzymes was not completely inhibited but only to $50 \%$ to $80 \%$ of its original activity (Table 1).

The subsequent stage of the studies involved application of cystatin isolated from hen egg proteins for inhibition of cathepsin $B$ and $L$ activities in the obtained homogenates of colorectal tumors. The estimations were performed in all the neoplastic samples and 20 control samples. The first stage involved determination of such an amount of the inhibitor which would inhibit cysteine peptidase activity in three randomly selected samples of homogenates. The results are presented in Table 2 .

The obtained results suggested that optimum results can be obtained inhibiting activity of cysteine peptidases in the studied tissue homogenates to the range of $50 \%$ to $60 \%$ of their original enzymatic activity. In samples of 60 homogenates obtained tissues of colorectal cancer the enzymatic activity was inhibited using $50 \mu \mathrm{g}$ cystatin per examined sample. The results are presented in Tables 3 and 4.

\section{Discussion}

This study demonstrates the potential for inhibiting cysteine peptidase activity in homogenates of tumorous tissues obtained from patients operated due to colorectal carcinoma using their specific inhibitors obtained from hen egg proteins. In normal cells, cysteine peptidases are contained in lysosomes, in which they catalyze protein degradation but do not fulfil as important functions as their analogs in cancer cells: in the latter they are secreted out of the cell or become attached to their membranes playing a direct role in processes of tumor aggression. Until now, the 
Table 4. Inhibition of cysteine peptidase activities in tissue homogenates from patients with colorectal carcinoma.

Estimations were conducted using spectrofluorometry, supplementing every sample of homogenate supernatant with $50 \mu \mathrm{g}$ inhibitor (activity of $344.8 \mathrm{U} / \mathrm{mg}$ protein)

\begin{tabular}{|c|c|c|c|}
\hline Sample no. & $\begin{array}{l}\text { Activity of cathepsin } B \\
\text { and } L / 1.0 \mathrm{mg} \text { protein }\end{array}$ & $\begin{array}{l}\text { Cathepsin } B \text { and } L+50 \mu g \\
\text { cystatin from egg protein }\end{array}$ & $\begin{array}{c}\text { \% inhibition of cathepsin } B \\
\text { and } L \text { activity }\end{array}$ \\
\hline 1 & 262.8 & 90.1 & 65.7 \\
\hline 2 & 345.5 & 156.2 & 54.8 \\
\hline 3 & 264.1 & 86.1 & 67.4 \\
\hline 4 & 253.3 & 125.1 & 50.6 \\
\hline 5 & 352.4 & 198.7 & 43.5 \\
\hline 6 & 215.4 & 96.1 & 55.4 \\
\hline 7 & 341.2 & 173.4 & 49.2 \\
\hline 8 & 313.1 & 207.9 & 33.6 \\
\hline 9 & 287.2 & 112.6 & 60.8 \\
\hline 10 & 366.4 & 171.8 & 53.1 \\
\hline 11 & 268.7 & 149.9 & 62.8 \\
\hline 12 & 237.5 & 124.5 & 41.2 \\
\hline 13 & 378.2 & 252.6 & 33.2 \\
\hline 14 & 193.4 & 111.2 & 42.5 \\
\hline 15 & 273.3 & 167.3 & 38.8 \\
\hline 16 & 172.1 & 94.3 & 45.2 \\
\hline 17 & 246.5 & 119.8 & 51.4 \\
\hline 18 & 294.2 & 107.1 & 63.6 \\
\hline 19 & 186.3 & 96.9 & 48.0 \\
\hline 20 & 260.1 & 118.3 & 54.5 \\
\hline 21 & 358.4 & 233.0 & 35.0 \\
\hline 22 & 268.8 & 138.2 & 48.6 \\
\hline 23 & 135.1 & 94.8 & 66.1 \\
\hline 24 & 242.5 & 137.3 & 43.4 \\
\hline 25 & 378.3 & 186.5 & 50.7 \\
\hline 26 & 279.6 & 136.2 & 51.3 \\
\hline 27 & 346.9 & 197.4 & 43.1 \\
\hline 28 & 357.5 & 175.5 & 50.9 \\
\hline 29 & 251.8 & 148.6 & 41.0 \\
\hline 30 & 403.2 & 162.5 & 59.7 \\
\hline 31 & 243.0 & 109.6 & 54.9 \\
\hline 32 & 238.9 & 123.5 & 48.3 \\
\hline 33 & 341.9 & 146.0 & 57.3 \\
\hline 34 & 251.7 & 142.2 & 43.5 \\
\hline 35 & 338.7 & 169.0 & 49.9 \\
\hline 36 & 361.4 & 221.5 & 38.7 \\
\hline 37 & 252.3 & 122.4 & 51.5 \\
\hline 38 & 239.9 & 121.9 & 49.2 \\
\hline 39 & 348.3 & 181.8 & 47.8 \\
\hline 40 & 339.1 & 167.5 & 50.6 \\
\hline
\end{tabular}


Table 4. continued

\begin{tabular}{|c|c|c|c|}
\hline 41 & 249.8 & 151.9 & 39.2 \\
\hline 42 & 189.2 & 80.2 & 57.6 \\
\hline 43 & 238.6 & 137.0 & 42.6 \\
\hline 44 & 277.1 & 143.3 & 48.3 \\
\hline 45 & 358.6 & 180.7 & 49.6 \\
\hline 46 & 249.1 & 126.8 & 49.3 \\
\hline 47 & 341.2 & 141.9 & 58.4 \\
\hline 48 & 271.9 & 141.1 & 48.1 \\
\hline 49 & 202.3 & 86.4 & 57.3 \\
\hline 50 & 368.1 & 141.3 & 61.6 \\
\hline 51 & 338.9 & 160.0 & 48.2 \\
\hline 52 & 287.3 & 125.6 & 56.3 \\
\hline 53 & 358.4 & 185.7 & 48.2 \\
\hline 54 & 283.7 & 159.7 & 43.7 \\
\hline 55 & 301.6 & 134.8 & 55.3 \\
\hline 56 & 259.5 & 137.8 & 46.9 \\
\hline 57 & 347.3 & 161.8 & 53.4 \\
\hline 58 & 248.9 & 126.4 & 49.2 \\
\hline 59 & 297.3 & 141.5 & 52.4 \\
\hline 60 & 232.1 & 122.6 & 47.2 \\
\hline Mean & 286.50 & 142.86 & 49.94 \\
\hline
\end{tabular}

involvement of matrix proteases, including metalloproteinases, serine and cysteine peptidases, was demonstrated in key functions linked to tumor development. It was shown that, apart from turnover of extracellular matrix, the enzymes are active in reciprocal autoactivation within the protein cascades, associated with tumor development. Recognition of the transformations promotes development of novel strategies of anti-neoplastic therapy, linked to inhibition of selected proteolytic enzymes in specific pathophysiological processes. Until now, it has been shown that enzymes of cysteine peptidase family fulfil key roles in processes of tumor development, such as apoptosis, angiogenesis, cell proliferation and invasion. Until now, the results have been confirmed mainly in cell lines of human tumors developing in transgenic mice $[19,20]$. Activity of cathepsins $B$ and $L$ was inhibited also in vivo, in the blood of patients with laryngeal cancer using autogenous inhibitors isolated from the urine of the patients [21] or placenta and amniotic fluid of experimental animals [22], while the subsequent source of inhibitor isolation involved egg proteins in order to obtain sufficient amounts of the inhibitor to perform a series of experiments, aimed at defining the potential of using the inhibitors to alter activity of enzymes linked to neoplastic processes in vivo [23]. The latter inhibitor was selected on purpose, since cystatin from hen eggs resembles in its structure autogenous cystatins present in the human body [14]. The inhibitor was also found to resemble in structure human cystatin $\mathrm{SN}$, the activity of which is strictly correlated with levels of typical tumor markers, such as CE or CE 19-9 in patients with colorectal carcinoma [13]. Another autogenic inhibitor, cystatin C, was examined as a potential factor able to control enzymes specific for neoplastic processes. Despite satisfactory results on neoplastic process control by autogenous inhibitors present in the patient's body, inhibitors of cysteine peptidases could not have been used in treatment due to a number of problems associated with production of e.g. cystatin C [24]. In other studies, cystatin of hen eggs has been used following its pre-labeling with radioactive iodine ${ }^{125} \mathrm{I}$.

This study aimed at using the inhibitor mainly to selectively label individual human cancer cells. The preparation was also used in an in vivo experiment obtaining delineation of tissues and organs in which human tumors developed following their grafting to transgenic mice. Employing scintigraphy, the ${ }^{125} \mathrm{I}-\mathrm{la}-$ beled cystatins bound in almost $98 \%$ only to cancerous cells, yielding in tumor-grafted animals clear outlines of organs in which the tumor developed [25]. 
Inhibitors isolated from egg protein or placenta were also used to determine sites of their binding in neoplastic tissues. The complexes were found to appear in sites with presence of cathepsin B or at the limit of neoplastic invasion. In preparations of neoplastic tissues obtained from cancerous patients, the sites in which enzyme-inhibitor complexes appeared were determined using a modified immunohistopathological technique [26, 27]. Inhibitors of cysteine peptidases may be applied in extracorporeal therapy or in preparation of new generation targeted drugs, taking advantage of affinity linked to cathepsin B, which is present in tumor cell membranes, affinity to nanocapsule-bound egg cystatin. The toxic cytostatic drug, isolated from a patient's body by the nanocapsule, will not be released until the nanocapsule reaches the site in the body with overexpression of cysteine peptidases or tissues manifesting tumorous traits. Moreover, a technique has been devised to remove from the blood of cancerous patients active cysteine peptidases or cancerous cells, which in their cell membranes carry the enzymes [28-30].

\section{Summary}

For years, attempts have continued to find inhibitors not toxic for the body which would be able to inhibit enzymatic processes associated with tumor development, including development of colorectal cancer. Such inhibitors include egg protein cystatins, genetically similar to their analogs present in the human body. They have been found to inhibit activity of cathepsins B and L, regarded as representing enzymes linked to key cancerous processes. Significant progress in the development of research involves the results of studies conducted in the Medical University in Wroclaw, in which a new, efficient and economic method has been designed to isolate the inhibitors on a broad scale. This allows for studies aimed at their use in vitro to inhibit neoplastic processes, and it opens up the possibility of a new trend in anti-neoplastic therapy, i.e. inhibitor therapy.

\section{Conclusions}

1. Activity of cathepsins B and L increases in the neoplastic tissues of the large intestine.

2. Cystatins from egg protein control the activity of cathepsins $\mathrm{B}$ and $\mathrm{L}$ in vitro in colorectal cancer tissue.

\section{References}

1. Yang VW, Lewis J, Wang TC, Rustgi AK. Colon cancer: an update and future directions. Gastroenterology. 2010;138: 2027-2028.
2. Smith RA, Cokkinides V, Brooks D, Saslow D, Brawley OW. Cancer screening in the United States: a review of current American Cancer Society guidelines and issues in cancer screening. CA Cancer J Clin. 2010;60:99-119.

3. Steindorf K, Tobiasz-Adamczyk B, Popiela T. Combined risk assessment of physical activity and dietary habits on the development of colorectal cancer. A hospital-based case-control study in Poland. Eur J. Cancer Prev. 2000;9:309-316.

4. Fazeli A, Steen RG, Dickinson SL et al. Effects of p53 mutations on apoptosis in mouse intestinal and human colonic adenomas. Proc Natl Acad Sci USA. 1997;94:10199-101204.

5. Andreyev HJ, Norman R, Cuningham D, Oates J, Costa JC. Kirsten ras mutations in patients with colorectal cancer: the "RASCAL II" study. Br J Cancer. 2001;85:692-696.

6. Skrzydlewska E, Sulkowska M, Koda M, Sulkowski S. Proteolytic-antiproteolytic balance and its regulation in carcinogenesis. World J Gastroenterol. 2005;11:1251-1266.

7. Schmitt M, Janicke F, Graeff H. Tumor-associated proteases. Fibrynolysis. 1992;6:3-18.

8. Curran S, Dundas SR, Buxton J, Leeman MF, Ramsay R, Murray GI. Matrix metalloproteinase/tissue inhibitors of matrix metalloproteinase phenotype identifies poor prognosis colorectal cancers. Clin Cancer Res. 2004;10:8229-8234.

9. Kuester D, Lippert H, Roessner A, Krueger S. The cathepsin family and their role in colorectal cancer. Pathol Res Pract. 2008;204:491-500.

10. Talieri M, Papadopoulou S, Scorilas A et al. Cathepsin B and cathepsin D expression in the progression of colorectal adenoma to cancer. Cancer Lett. 2002;205:97-106.

11. Cavallo-Medved D, Mai J, Dosescu J, Sameni M, Sloane BF. Caveolin-1 mediates the expression and localization of cathepsin B, pro-urokinase plasminogen activator and their cell-surface receptors in human colorectal carcinoma cells. J Cell Sci. 2005;118:1493-1503.

12. Lah TT. Kos J. Cysteine proteinases in cancer progression and their clinical relevance for prognosis. Biol. Chem. 1998; 379:125-130.

13. Yoneda $\mathrm{K}$, Iida $\mathrm{H}$, Endo $\mathrm{H}$ et al. Identification of cystatin $\mathrm{SN}$ as a novel tumor marker for colorectal cancer. Int J Oncol. 2009;35:33-40.

14. Saitoh E, Isemura S, Sanada K. Cystatin superfamily. Evidence that family II cystatin genes are evolutionary related to family III cystatin genes. Biol Chem Hoppe-Seyler. 1988;369:191-197.

15. Sobin LH, Wittekind C. Edit. TNM. Classification of malignant tumors. $5^{\text {th }}$ ed. New York, USA, Wiley-Liss, Inc. 1997.

16. Barrett AJ, Kirschke H. Cathepsin B, cathepsin H, and cathepsin L. Methods Enzymol. 1981; 80:535-561.

17. Heidtman HH, Salge U, Abrahamson M et al. Cathepsin B and cysteine proteinase inhibitors in human lung cancer cell lines. Clin Exp Metastasis. 1997;15:368-381.

18. Bradford MM. A rapid and sensitive method for the quantitation of microgram quantities of protein utilising the principle of protein-dye binding. Anal Biochem. 1976;72:248-254.

19. Affara NI, Andreu P, Coussens LM. Delineating protease functions during cancer development. Methods Mol Biol. 2009;539:1-32.

20. Mohamed MM, Sloane BF. Cysteine cathepsins: multifunctional enzymes in cancer. Nat Rev Cancer. 2006;6:764-775.

21. Siewinski M. Autologous cysteine peptidase inhibitors as potential anticancer drugs. Anti-Cancer Drugs. 1993;4:97-99.

22. Sebzda T, Saleh Y, Siewinski M, Rudnicki J, Ziolkowski P. The influence of vitamin $E$ and human placenta cysteine peptidase inhibitor on the expression of cathepsin B and L implanted hepatoma Morris 5123 tumor model in the Wistar rats. World J Gastroenterol. 2005;11:587-592. 
23. Siewiński M, Berdowska I, Jarmułowicz J. Method of isolating cysteine peptidase inhibitors from plants and chicken white eggs. Patent PL. 1998;174636.

24. Keppler D. Towards novel anti-cancer strategies based on cystatin function. Cancer Lett. 2006;235:159-176.

25. Czecior E, Szymaniec S, Siewinski M, Fortuna W, Międzybrodzki W. A potential use of cystein peptidase inhibitors in radiodiagnostics of upper respiratory tract tumors. Otolaryng (Pol). 2002;LVI,5:573-576.

26. Saleh Y, Siewinski M, Sebzda T et al. Inhibition of cathepsin $\mathrm{B}$ activity in human breast cancer tissue by cysteine peptidase inhibitor isolated from human placenta - immunohistochemical and biochemical studies. Folia Histochem Cytobiol. 2003;41:161-167.

27. Saleh Y, Wnukiewicz J, Trziszka T, Siewinski M, Ziolkowski P, Kopec W. Cathepsin B and cysteine protease inhibitors in human tongue cancer: correlation with tumor staging and in vitro inhibition of cathepsin B by chicken cystatin. $J$ Cancer Molecules. 2006;2:67-72.

28. Hap A, Kielan W, Siewinski M et al. Inhibition of selected enzymes with specific inhibitors in the tissue homogenates from patients with colorectal cancer. Pol J Surg. 2010;82: 894-903.

29. Siewinski M, Bryjak M, Sebzda T et al. A system and method for the extra-corporeal purification of blood of pathogenic enzyme. Patent Cooperation Treaty (PCT) Akademia Medyczna we Wroclawiu PCT/PL2007/000060; 2007.

30. Siewiński M, Jarmulowska-Malolepsza K, Witkiewicz W et al. Nanocapsules intended for transferring toxic drugs to the sites of invasive diseases occurrence in a patient body and method of their preparation PCT/PL2010/050017; 2010.

Submitted: 5 November, 2010

Accepted after reviews: 17 March, 2011 